\title{
UM MODELO DE ANÁLISE SÓCIO-ECONÔMICA: CONSTRUÇÃO E RESULTADOS OBTIDOS
}

\author{
Vera Lúcia S. Botta Ferrante* \\ Valdemar Vertuan* \\ Benedicto Egbert Correa de Toledo **
}

\begin{abstract}
RSPU-B/311
Ferrante, V. L. S. B. et al. - Um modelo de análise sócio-económica: construção e resultados obtıdos. Rev. Saúde públ., S. Paulo, 10:177-90, 1976.

Resumo: Apresenta-se um modelo de análise sócio-econômica, construido com o objetivo de chegar a um escalonamento possivel da posição de uma determinada população na estrutura da sociedade. Tal modelo foi construído a partir de um conjunto de indicadores previamente selecionados como os mais significativos para a avaliação do nivel sócio-econômico da população amostrada. Pretendeu-se, com a construcão desse modelo, mostrar a interferéncia de fenômenos de natureza sócio-econômica na ocorréncia de determinados problemas bucais. A investigação mostrou a seguinte composição da população estudada: baixa inferior, 21,8\%; baixa superior, $39,9 \%$; média inferior, $26,6 \%$; média superior, 9,1\%; alta inferior, $1, \% \%$ e alta superior, $0,5 \%$.
\end{abstract}

Unitermos: Modelo sócio-económico. Análise sócio-econômica. Nirel sócio-econômico.

\section{N T R O DUC I O}

De maneira geral, na avaliação de classes sociais. constata-se o privilegiamento de um critério de medida, ora a profissão, ora o rendimento ou a instrução ${ }^{11}$.

A partir de uma colocação mais globalizante, aceita-se que a explicitação das razóes que levam os indivíduos a ocupar diferentes posiçôes na estrutura da sociedade, exige a não fixação de um único critério de hierarquização social.

Evidentemente. a construção de uma medida de estratificação social é um problema de uma certa complexidade. Como construir medidas corretas das variáveis estratificatórias, que por sua própria natureza. não são fenômenos que apresentam um caráter facilmente mensurável. de dimensões quantificáveis? Esses problemas, de certa forma, funcionam como limites que se impõem ao investigador.

No casso dessa pesquisa. aliado a esses limites. deve ser apontado um outro fator: não se tinha propriamente a pretensão teórica de se estudar apenas a situação sócio-econômica de escolares e de se lidar com o conceito de classe social como instrumento analítico de diferenciação estrutural da sociedade. Procurava-se encontrar uma maneira empírica, concreta. de

* Da Faculdade de Filosofia, Clënclas e Letras de Araraquara - Campus Lnnversitário Araraquara, SP - Brasil.

* Da Faculdade de Farmácia e Odontologia de Araraquara - Rua Expedicionários do Brasil, 1.621 - Araraquara, SP - Brasil. 
FERRANTE, V. L. S. B et al, - Lm modelo de análise sócio-económica: construcão e resultados obtidos Rev: Saude publ., S. Paulo, 10:177-90, 1976.

acesso a uma escala de hierarquização social.

Diante disso. deixou-se de lado os problemas teóricos existentes nas tentativas de se analisar a situação sócio-econômica. através da operacionalização do conceito classe social, e optou-se por uma maneira possível - a que se apresentava mais acessivel diante dos instrumentos de análise de que se dispunha - para avaliar o nível sócio-econômico da população inrestigada, embora houresse consciência de que essa solução poderia apresentar deficiências e uma certa precariedade.

Procurou-se atender a uma solicitação de ordem prática e se construir um modelo de análise sócio-econômica suficientemente flexível, passível de ser empregado juntamente com outros elementos de estudo epidemiológico. em trabalhos de relacionamento das condições bucais objetivo da pesquisa onde se empregou $o$ modelo que será apresentado ${ }^{12}$ — ou de outros problemas, com a posição sócio-econômica dos indivíduos.

\section{MATERIAL E MÉTODOS}

\section{Material}

Foram relacionados 1.753 escolares dos 14 estabelecimentos da rede estadual de ensino do $1 .^{\circ}$ grau de Araraquara. correspondendo a $20.5 \%$ do universo. Como este trabalho incluía também os pais ou responsáveis dos escolares. uma amostra relativamente grande foi empregada, diante da expectativa de ocorrer uma perda parcial. o que realmente se verificou pois. o estudo foi concluído com a colaboração de $70.3 \%$ dos indivíduos sorteados. reduzindo-se a amostra a 1.233 elementos. (11) s-ja. $14.4^{c} c_{r}$ do universo.

\section{Método.}

Apos " "ame clinico bucal. como parte dos objetion da pesquisa. com cada um dos escolares era realizada uma entrevista para verificação de suas aspirações. modo de vida. hábitos e cuidados orais.

Em outra etapa, era enviado um questionário aos pais ou responsáveis de cada escolar examinado. destinado a qualificar a familia dentro de um nível sócio-econômico*.

Embora tivesse sido elaborado um roteiro, em princípio, adequado à capacidade de compreensão da população. no dia da devoluçāo. entrevistava-se o portador. geralmente os pais, para uma confirmação das respostas obtidas.

\section{O modelo proposto}

Partiu-se da consideração de que um modelo de análise sócio-econômica deveria ser decorrência da composição hierárquica de um conjunto de indicadores que revelassem de que determinados fatores são responsáveis, em maior ou menor grau, pela fixação dos indivíduos em diferentes posiçōes na estrutura da sociedade.

Não se pretendeu na construção desse modelo uma simples adequação aos instrumentos teóricos de análise utilizados pelos sociólogos americanos ${ }^{13},{ }^{13}$.

Evidentemente. esses instrumentos foram tomados como referência inicial, mas para fazer do modelo proposto. não um esquema teórico-abstrato. mas um elemento flexivel de captação da realidade empírica. foi realizada uma pesquisa piloto com alguns pais de escolares, na qual foram levantados os dados significativos para a construção dos indicadores componentes: do modelo.

Obtidos tais dados, procedeu-se a uma avaliação e posterior hierarquização dos indicadores. e como produto desse procedimento lógico. chegou-se à composiçāo final do modelo. que foi ampliado em relação aos utilizados pelos sociólogos americano: ${ }^{11}, 1: 3$. visando justamente maior

* Ver err anexo parte do questionámo utulizado. 
FERRANTE, V. L. S. B. et al. - Um modelo de análise sócio-econômica: construçāo e resultados obtidos. Rev. Saúde puibl., S. Paulo, 10:177-90, 1976.

adequação à realidade investigada. Procurou-se com a proposição de um modelo combinado de vários indicadores sócio-econômicos. obter um controle mais direto das variáveis subjetivas (esperado por se ter utilizado como técnica de pesquisa, o questionário) e uma maneira de evitar as falhas constatadas nas análises estratificatórias baseadas num único índice de medida de "status".

\section{Componentes do modelo}

Reconhecendo a validade "relativa" das colocações de classes sociais definidas por Costa Pinto ${ }^{2}$, Ossowski ${ }^{10}$ e Stavenhagen ${ }^{11}$, embora as mesmas incidam sobre um rumo teórico não objetivado neste trabalho, procurou-se elaborar uma escala de indicadores semelhante à proposta por Guidi \& Duarte ${ }^{5}$, que envolvesse um maior número de critérios, dispostos de maneira tal. que se pudesse, o mais objetivamente possível. dimensionar o "status" total do indiríduo.

O modelo proposto baseia-se fundamentalmente em 7 indicadores:

$$
\begin{aligned}
& \text { A - área de habitação; } \\
& \text { B - nível ocupacional; } \\
& \text { C - rendimento mensal da família; } \\
& \text { D - níel de instrução; } \\
& \text { E - características da moradia; } \\
& \text { F - tipo de residência; } \\
& \text { G - conforto doméstico. }
\end{aligned}
$$

Este modelo aceita como princípio de hierarquização, a divisão da comunidade em 6 estratos sociais: alto superior, alto inferior. médio superior. médio inferior, baixo superior e baixo inferior.

A família, considerada como um subsistema social, foi tomada como unidade global de referência. Apesar do problema bucal focalizado neste estudo ter sido cientificamente pesquisado em escolares, em vista da exigência de equacioná-lo em função de variáveis sócio-econômicas, os dados coletados foram centralizados sobre as situações de existência social do grupo familiar em que o mesmo estava inserido.

Para a aplicação deste modelo, a cada um dos indicadores eram atribuídos pesos que variavam de 1 a 7 de acordo com uma estratificação hirerárquica de situações, para que, no final do inquérito, sua soma representasse a classificação do indivíduo na escala social. Os pesos foram atribuídos em ordem decrescente de prestígio social. A escala de hierarquização social utilizada foi a seguinte:

$$
\begin{aligned}
\text { N. de pontos } & \begin{array}{c}
\text { Escala de medida de } \\
\text { estratificação social }
\end{array} \\
7-11 & \text { Classe alta superior } \\
12-16 & \text { Classe alta inferior } \\
17-24 & \text { Classe média superior } \\
25-32 & \text { Classe média inferior } \\
33-40 & \text { Classe baixa superior } \\
41-49 & \text { Classe baixa inferior }
\end{aligned}
$$

Para a construção dessa hierarquia, foram observadas situaçōes peculiares da comunidade de Araraquara e outros estudos de estratificação social referentes ao mesmo problema. Assim. serão descritos os critérios utilizados na determinação de cada um dos indicadores.

\section{A -- Area de habitação}

Critério específico da comunidade de Araraquara - evidentemente, deverá ser adaptado às situaçôes de outras, no caso de sua utilização - fixado a partir do local de habitação do individuo.

A hierarquização foi fruto de uma verificação empírica - fase do plano piluto - na qual mostrou ser pertinente a correlação entre a posição sócio-econômica e o local de moradia. Verificou-se que as áreas de habitação fixadas apresentaram, diante da própria população local, um consenso a respeito do respectivo prestígio social e status dos seus moradores. 
FERRANTE, V. L. S. B. et al, - Um modelo de análise sócio-econômica: construção e resultados obtidos. Rev. Saude públ., S. Paulo, 10:177-90, 1976.

O estabelecimento dos pesos neste indicador veio de observaçōes — a respeito do estilo de vida, meio de transporte, um certo grau de padronização no nível das residências - colhidas entre os moradores dos diferentes bairros e decorrentes do próprio conhecimento dos investigadores da diferenciação de prestígio existente entre os bairros da cidade.

Fixou-se a seguinte distribuição:

Peso 1 - Bairro da Fonte Luminosa;

Peso 2 - Centro;

Peso 3 - Bairro do Carmo;

Peso 4 - Bairro de São Geraldo e Santana;

Peso 5 - Bairro da Vila Xavier e São José;

Peso 6 - Vilas Populares e assemelhadas;

Peso 7 - Outros bairros da periferia, de localização mais distante e reputação duvidosa.

\section{B - Nivel ocupacional do pai ou pessoa responsável}

Objetivou-se, com esta variável, obter dados sobre a ocupação principal do chefe da família, isto é, aquela que lhe absorvesse maior tempo e que contribuísse como fonte prioritária da renda familiar. Para os inativos (inválidos - permanentes ou temporários, aposentados, desempregados), foram coletados dados sobre a última ocupação.

Este indicador era analisado pelo emprego de uma escala de hierarquia de prestígio das ocupações de Glass ${ }^{4}$, que aponta uma correlação positiva entre ocupação usada como índice de "status" social e níveis de instrução e renda. Esta escala tem sido empregada na Inglater$\mathrm{ra}^{6}$, sendo também aplicada primeiramente no Brasil, em São Paulo por Hutchinson $^{8}$ e, posteriormente, por outros através do Centro Brasileiro de Pesquisas Educacionais ${ }^{1,5}$.
Uma pesquisa efetuada por Dias ${ }^{3}$, em São Paulo, apresentou uma modificação da escala original de Hutchinson, quando subdividiu as faixas de ocupação e adicionou uma escala para ocupaçôes rurais.

Optou-se pela aplicação da escala proposta por Dias, por se adaptar melhor às situações de nossa região e aos interesses do estudo.

A escala é a seguinte:

Peso 1 - Altos cargos políticos e administrativos; proprietários de grandes empresas e assemelhalhadas; proprietário com grande extensão de terra e grande número de empregados.

Peso 2 - Profissões liberais; cargos de gerência ou direção; proprietários de empresa de tamanho médio; proprietário de área menor, porém ainda um grande fazendeiro.

Peso 3 - Posições mais baixas de supervisão ou inspeção de ocupações não manuais; proprietários de pequenas empresas comerciais e industriais; proprietário rural, fazendo todo o trabalho com maquinaria ou tendo pequeno número de empregados.

Peso 4-Ocupações não manuais de rotina e assemelhados; pequeno proprietário rural.

Peso 5 - Supervisor de trabalho manual e ocupações assemelhadas; proprietário de área muito pequena, fazendo todo o trabalho manual com um ou nenhum empregado.

Peso 6 - Ocupações manuais especializadas e assemelhadas; agricultor que trabalha em terra alheia, dividindo os lucros com o proprietário. 
FERRANTE, V. L. S. B. et al. - Um modelo de análise sócio-econômica: construção e resultados obtidos. Rev. Saúde públ., S. Paulo, 10:177-90, 1976.

Peso 7 - Ocupações manuais não especializadas; trabalhador rural assalariado.

Existe uma descrição pormenorizada das ocupações distribuídas em cada categoria e isso, de certa forma, veio contornar a possível arbitrariedade que se teria na distribuição das ocupaçóes *.

\section{$\mathrm{C}$ - Rendimento mensal da família}

Considerou-se o salário mínimo como unidade básica de medida e em função da informação obtida, o rendimento mensal familiar foi equacionado pelas seguintes faixas salariais:

Peso 1 - mais de 20 salários mínimos; Peso 2 - de 15 a 20 salários mínimos;

Peso 3 - de 10 a 15 exclusive salários mínimos;

Peso 4 - de 6 a 10 exclusive salários mínimos;

Peso 5 - de 3 a 6 exclusive salários mínimos;

Peso 6 - de 1 a 3 exclusive salários mínimos;

Peso 7 - menos de 1 salário mínimo.

Este indicador foi resultado da soma de rendas individuais de cada membro da família, desde que o mesmo contribuísse, parcial ou integralmente, para a cobertura das despesas do orçamento doméstico. Quando um elemento percebia uma certa renda, mas não colaborava em nada com a despesa familiar, esta não foi computada para a análise do indicador.

\section{D - Grau de escolarização}

Este indicador leva em consideração o grau de escolarização do pai, da mãe ou pessoa responsável pela criança.
Tem-se então a seguinte escala:

Peso 1 - curso superior (completo ou incompleto);

Peso 2 - II ciclo (completo ou incompleto) ;

Peso 3 - I ciclo (completo ou incompleto);

Peso 4 - primário completo;

Peso 5 - primário incompleto;

Peso 6 - sabe ler e escrever;

Peso 7 - analfabeto.

Os critérios 5 e 6 são bastante diferenciados, pois foi usada como norma, para sua interpretação, o fato de que os indivíduos do peso 5 seriam aqueles que, mesmo não tendo completado os primeiros quatro anos do curso do $1 .^{\circ}$ ciclo (ex-curso primário), receberam, em maior ou menor escala, uma forma de educação sistemática.

Já os de peso 6 seriam aqueles semialfabetizados, que, mesmo apresentando dificuldades no desempenho da leitura e redação, tenham aprendido a ler e a escrever assistematicamente.

\section{$\mathrm{E}-$ Características da moradia}

A referência às características da moradia como índice de estratificação social apresenta suporte teórico principalmente nas análises realizadas a esse respeito por sociólogos americanos ${ }^{13}$. Os critérios para o seu escalonamento contém um certo grau de arbitrariedade, exteriorizado na maneira como foram combinados o fato de se tratar de uma casa própria ou alugada, o montante do aluguel e o tamanho da mesma.

Entretanto, a análise feita não se restringiu às informações pessoais dadas pelos sujeitos da amostra, falha constatada nos estudos acima referidos. Hou-

* A referida descrição das ocupaçôes poderá ser observada no trabalho de tese de doutoramento do Prof. Valdemar Vertuan ${ }^{12}$, da Faculdade de Farmácla e Odontologia de Araraquara. 
FERrante, V. L. S. B et al. - Um modelo de análise sócio-econômica: construção e resultados obtidos Rev. Salide pibl., S. Paulo, 10:177-90, 1976.

ve uma observação cuidadosa por parte dos investigadores. das condições de moradia do entrevistado.

A aceitação desse critério justifica-se, em última instância, por se considerar que a propriedade ou não de um bem e a situação em que o mesmo se apresenta (tamanho e montante do aluguel pago) são elementos auxiliares significativos para a apreensão das diferenças estratificatórias existentes em uma comunidade.

Ltilizou-se a seguinte escala:

Peso 1 - casa própria com mais de 7 cômodos;

Peso 2 - casa própria de 5 a 7 cômodos;

Peso 3 - casa própria de 3 a 5 cômodos;

Peso 1 - Casa própria com menos de 3 cômodos:

Peso 5 - casa alugada pagando mais de 1.3 salários:

Peso 6 - casa alugada pagando de 0,4 a 1.3 salários;

Peso 7 - casa alugada pagando menos de 0.4 salários.

Para computação, não foram considerados cômodos o terraço, área e corredores.

As considerações teóricas e empíricas feitas para este indicador são válidas para os seguintes $F$ e $G$.

\section{F - Tipo de residência}

Os critérios utilizados para este indicador foram: condições de paredes, piso, cobertura (material com que era construída) e número de cômodos.

A combinação dos mesmos deu origem à seguinte escala:

Peso 1 - casa forrada, com piso de taco ou assoalho. paredes de tijolos, cobertura de telha ou lajota, jardim. com 10 cômo-dos ou mais;
Peso 2 - casa forrada, com piso de taco ou assoalho, paredes de tijolos, cobertura de telha ou lajota, jardim, de 7 a 10 cômodos:

Peso 3 - casa forrada, piso de taco ou assoalho, paredes de tijolos, cobertura de telha ou lajota, sem jardim, de 5 a 7 cômodos:

Peso 1 - casa forrada ou parcialmente forraja, piso de taco ou assoalho ou ladrinhos, paredes de tijolos, cobertura de telha, sem jardim. com menos de 5 cômodos;

Peso 5 - casa sem forro, piso de assoalho, paredes de tijolos, teto de telha, sem jardim, com mais de 5 cômodos;

Peso 6 - casa sem forro, piso de ladrilhos ou cimentado, paredes de tijolos, teto de telha, de 3 a 5 cômodos;

Peso 7 - casa sem forro, piso de chão batido, paredes de madeira ou barro, teto sem ser de telha, com menos de 3 cômodos.

\section{G - Conforto doméstico}

Para análise deste indicador, foram empregados, como critérios. a existência na habitação da família. de: luz elétrica, água encanada, tipo de mobília e número de aparelhos eletrodomésticos.

Construiu-se a seguinte escala:

Peso 1 - luz elétrica, água encanada, mobiliada luxuosamente, possuindo de 6 para mais aparelhos eletro-domésticos;

Peso 2 - luz elétrica, água encanada, mobiliada regularmente (pou- 
FERRANTE, V. I. S. B, et al. - Um modelo de análise sócio-econômica: construção e resultados obtidos Rev. Saúde públ., S. Paulo, 10:177-90. 1976.

co luxo), possuindo de 6 para mais aparelhos eletro-domésti$\cos$ :

Peso 3 - luz elétrica, água encanada, mobiliada regularmente (sem luxo) possuindo de 4 a 6 aparelhos eletro-domésticos;

Peso 4 - luz elétrica, água encanada, mobiliada regularmente, possuindo 4 aparelhos eletro-domésticos;

Peso 5 - luz elétrica, água encanada, mobiliada abaixo de regularmente (simplesmente), poucos móveis, nada de consumo supérfluo, possuindo de 2 a 4 aparelhos eletro-domésticos;

Peso 6 - luz elétrica, água encanada, poucos móveis, mobiliada bem simples, possuindo menos de 2 aparelhos eletro-domésticos;

Peso 7 - sem luz elétrica ou sem água, podendo ter ou não água encanada, praticamente sem mobília (pobre), possuindo menos de 2 aparelhos eletro-domésticos.

\section{Observações finais a respeito} do modelo proposto

Mesmo considerando que a orientação da sociologia americana deixa a desejar na explicação do fenômeno classe social, principalmente porque a apreensão das variáveis sócio-comunitárias é geralmente expressão de critérios subjetivos nominais, optou-se por esta linha teórica, por ter este trabalho se desenvolvido numa comunidade e por apresentar a mesma, maiores recursos técnicos para se ter uma visão senão inteiramente explicativa, pelo menos ilustrativa do fenômeno classe social.
RESULTADOS E DISCUSSÃO

Após a aplicação das entrevistas avaliadoras das condiçōes sócio-econômicas, a amostra estudada apresentou-se distribuída dentro das várias classes sociais segundo as tabelas que se seguem:

Pelos resultados obtidos neste estudo, observou-se que teve sentido a hierarquização da população em 6 estratos e que a mesma obedeceu a padrões definidos de diferenciação.

O modelo de análise sócio-econômica proposto mostrou-se com boa aplicabilidade. pois os resultados obtidos no seu emprego na região pesquisada (Tabelas 1 e 2 ). estão bem próximos dos encontrados por outros pesquisadores diante de estudos globais.

Observem-se a respeito. comparativamente, os dados obtidos e os citados por Havighurst'. para os ELA. Grä-Bretanha. Austrália e Brasil e. os de Warner e Lunt ${ }^{13}$ também para os ELA.

Acrescente-se poder complementar a hierarquização proposta, com dados sobre consumo alimentar, nível de vida, vivência sócio-cultural (participação em atividades religiosas, culturais, clubes recreativos. sindicatos de classe, etc.), condições da educação dos filhos e aspirações sócio-profissionais dos mesmos, além de indicações de cuidados dentais, condições assistenciais, dados esses que vieram comprovar a hipótese inicial deste estudo de que o projeto de vida dos seis estratos da população investigada é diferenciada econômica, social e culturalmente por ser a mesma estruturalmente estratificada.

Esse instrumento de medida da situação sócio-econômica que foi empregado pode ser usado em outras análises que se proponham correlações do tipo da que foi estudada.

Como elemento comprobatório podem ser citados os resultados de problemas bucais obtidos paralelamente aos dados 
FERRANTE, V. L. S. B. et al. - Um modelo de análise sócio-econômica: construcăo e resultados obtidos. Rev. Saúde públ., S. Paulo, 10:177-90, 1976.

TABELA 1

Distribuição da população amostrada na hierarquização social proposta, segundo as idades e sexos

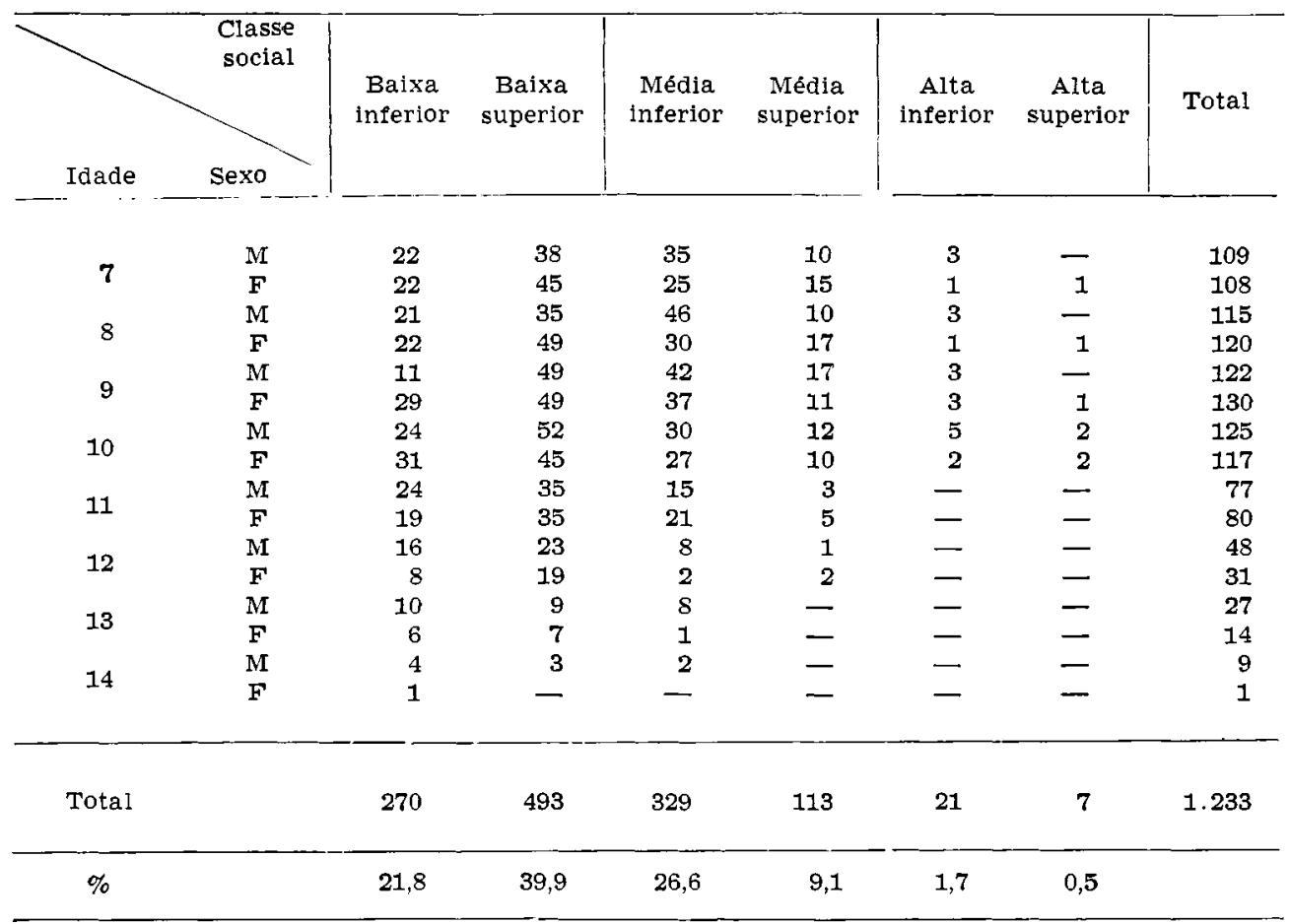

TABEI A 2

Distribuição da população amostrada na hierarquização social proposta, segundo as racas e sexos

\begin{tabular}{|c|c|c|c|c|c|c|c|c|}
\hline Raça & $\begin{array}{l}\text { Classe } \\
\text { social }\end{array}$ & $\begin{array}{l}\text { Baixa } \\
\text { inferior }\end{array}$ & $\begin{array}{l}\text { Baixa } \\
\text { superior }\end{array}$ & $\begin{array}{l}\text { Média } \\
\text { inferior }\end{array}$ & $\begin{array}{l}\text { Média } \\
\text { superior }\end{array}$ & $\begin{array}{c}\text { Alta } \\
\text { infertor }\end{array}$ & $\begin{array}{c}\text { Alta } \\
\text { superior }\end{array}$ & Todos \\
\hline $\begin{array}{c}\text { Branca } \\
\%\end{array}$ & $\begin{array}{l}\mathrm{M} \\
\mathrm{F}\end{array}$ & $\begin{array}{l}63 \\
59 \\
15,9\end{array}$ & $\begin{array}{l}157 \\
170 \\
42,8\end{array}$ & $\begin{array}{c}122 \\
96 \\
28,5\end{array}$ & $\begin{array}{c}41 \\
34 \\
9,8\end{array}$ & $\begin{array}{l}9 \\
7 \\
2,0\end{array}$ & $\begin{array}{l}3 \\
3 \\
0,7\end{array}$ & $\begin{array}{c}395 \\
369 \\
61,9\end{array}$ \\
\hline $\begin{array}{c}\text { Negra } \\
\%\end{array}$ & $\begin{array}{l}\mathrm{M} \\
\mathrm{F}\end{array}$ & $\begin{array}{l}64 \\
76 \\
37,3\end{array}$ & $\begin{array}{l}75 \\
73 \\
39,2\end{array}$ & $\begin{array}{l}39 \\
37 \\
20,2\end{array}$ & $\begin{array}{l}1 \\
9 \\
2,6\end{array}$ & $\frac{1}{0,2}$ & - & $\begin{array}{c}180 \\
195 \\
30,4\end{array}$ \\
\hline$\underset{\%}{\text { Amarela }}$ & $\begin{array}{l}\mathrm{M} \\
\mathrm{F}\end{array}$ & $\begin{array}{l}\mathbf{5} \\
\mathbf{3} \\
8,5\end{array}$ & $\begin{array}{c}12 \\
6 \\
19,1\end{array}$ & $\begin{array}{l}25 \\
10 \\
37,2\end{array}$ & $\begin{array}{l}11 \\
17 \\
29,7\end{array}$ & $\frac{4}{4,2}$ & $\begin{array}{l}\overline{1} \\
1,0\end{array}$ & $\begin{array}{c}57 \\
37 \\
7,6\end{array}$ \\
\hline Total & $\begin{array}{l}\mathrm{M} \\
\mathrm{F} \\
\%\end{array}$ & $\begin{array}{c}132 \\
138 \\
21,8\end{array}$ & $\begin{array}{c}244 \\
249 \\
39,9\end{array}$ & $\begin{array}{l}186 \\
143 \\
26,6\end{array}$ & $\begin{array}{l}53 \\
60 \\
9,1\end{array}$ & $\begin{array}{c}14 \\
7 \\
1,7\end{array}$ & $\begin{array}{r}3 \\
4 \\
0,5\end{array}$ & $\begin{array}{r}632 \\
601 \\
-\end{array}$ \\
\hline Total geral & & 270 & 493 & 329 & 113 & 21 & 7 & 1.233 \\
\hline
\end{tabular}


FERRANTE, V. L. S. B. et al. - Um modelo de análise sócio-econômica: construçáo e resultados obtidos, Rev. Saíde públ., S. Paulo, 10:177-90, 1976.

apresentados, pela aplicação de índices específicos.

Quanto ao índice de doenças periodontais, os níveis sociais influíram diferentemente, com uma tendência das classes mais inferiores mostrarem resultados mais elevados (Tabela 4).

Através da Tabela 5, vê-se que: a classe baixa inferior apresentou média de doenças periodontais (IP) igual à da baixa superior e diferente das apresentadas pelas média inferior, média superior e alta; a classe baixa superior apresentou média de IP diferente das apresentadas pelas média inferior, média superior e alta; a classe média inferior apresentou média de IP diferente das apresentadas pelas média superior e alta e a média su- perior e alta apresentaram médias de IP iguais.

Tais valores significam que os problemas periodontais tendiam a maior severidade nas pessoas de classes sociais inferiores, mostrando que referidas alteraçôes estão associadas aos fatores sócio-econômicos, condicionantes da sua origem e desenvolvimento.

$\mathrm{Na}$ verificação das condições de higiene oral, as classes sociais inferiores apresentaram os piores resultados, com as médias mais altas (Tabela 4).

Pela Tabela 6 vê-e que as classes sociais apresentaram, duas a duas, efeitos diferentes para o índice de higiene oral, pois comparando as suas respectivas médias vê-se que elas são diferentes duas a duas.

TABELA 3

Distribuição por países segundo as classes sociais

\begin{tabular}{l|l|l|l|l|l}
\hline $\begin{array}{c}\text { Grä- } \\
\text { Classe } \\
\text { Social }\end{array}$ & EUA* & Austrália * & Brasil *tanha & EUA ** & $\begin{array}{c}\text { Resultados } \\
\text { obtidos da } \\
\text { amostra }\end{array}$ \\
\hline
\end{tabular}

$\begin{array}{lrrrrrr}\text { Alta } & \mathbf{3} & 3 & 2 & 2 & 3,0 & 2,2 \\ \text { Média alta } & \mathbf{1 0} & 7 & 6 & 3 & 10,22 & 9,1 \\ \text { Média inferior } & 30 & 20 & 18 & 12 & 28,12 & 26,6 \\ \text { Baixa alta } & 40 & 50 & 54 & 33 & 32,6 & 39,9 \\ \text { Baixa inferior } & 17 & 20 & 20 & 50 & 25,22 & 21,8 \\ & & & & & \end{array}$

TA B E A 4

Distribuição das médias dos índices de cárie (CPO), doenças periodontais (IP) e higiene oral (IHO) nas várias classes suciais

\begin{tabular}{|c|c|c|c|}
\hline \multirow[b]{2}{*}{ Classe social } & \multicolumn{3}{|c|}{ Indices } \\
\hline & $\mathrm{CPO}$ & IP & IHO \\
\hline Baixa inferior & 3,5 & 1,74 & 1,6 \\
\hline Baixa superior & 3,0 & 1,43 & $\overrightarrow{1,4}$ \\
\hline Média inferior & 2,5 & 1,22 & 1,2 \\
\hline Média superior & 2,5 & 0,95 & 0,9 \\
\hline Alta inferior & 2,0 & 0,68 & 0,9 \\
\hline Alta superior & 24 & 0.58 & 0,8 \\
\hline
\end{tabular}


FERRANTE, V. L. S. B. et al. - Um modelo de análise sócio-econômica: construção e resultados obtidos. Rev. Saúde públ., S. Paulo, 10:177-90, 1976.

\section{T A B ELA 5}

Mórulo da diferença de médias do indice periodontal (IP), com respectivos desvio-padrão e valor de t-Student

\begin{tabular}{|c|c|c|c|c|c|}
\hline Classe social & Baixa & superior & Média inferior & Média superior & Alta \\
\hline Baixa inferior & $\begin{array}{l}(1) \\
(2) \\
(3)\end{array}$ & $\begin{array}{l}0021 \text { n.s. } \\
0,031 \\
0,871\end{array}$ & $\begin{array}{l}0, \mathbf{1 0 5} * * \\
0,031 \\
\mathbf{3 , 3 8 7}\end{array}$ & $\begin{array}{l}0,202^{* *} \\
0,033 \\
6,121\end{array}$ & $\begin{array}{l}0,271^{*} \\
0,042 \\
6,452\end{array}$ \\
\hline Baixa superior & & - & $\begin{array}{l}0,078^{*} \\
0,031 \\
2,516\end{array}$ & $\begin{array}{l}0,175^{* *} \\
0034 \\
5,147\end{array}$ & $\begin{array}{l}0,244^{* *} \\
0,042 \\
5,809\end{array}$ \\
\hline Média inferior & & 一 & - & $\begin{array}{l}0,097^{* *} \\
0,033 \\
2,939\end{array}$ & $\begin{array}{l}0,166^{* *} \\
0042 \\
3,952\end{array}$ \\
\hline Média superior & & - & 一 & 一 & $\begin{array}{l}0,069 \text { n.s. } \\
0,044 \\
1,568\end{array}$ \\
\hline
\end{tabular}

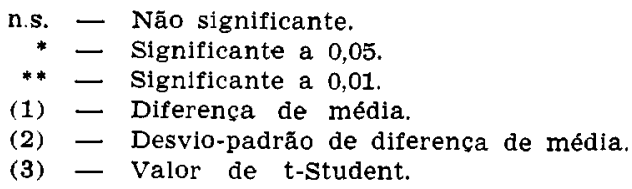

TABELA 6

Módulo da diferença de médias do indice de higiene oral (IHO), com respectivos desvios-padrão e valor t-Student

\begin{tabular}{|c|c|c|c|c|c|}
\hline Classe social & Baixa & superior & Média inferior & Média superlor & Alta \\
\hline Baixa inferior & $\begin{array}{l}(1) \\
(2) \\
(3)\end{array}$ & $\begin{array}{l}0,065^{* *} \\
0,021 \\
3,095\end{array}$ & $\begin{array}{l}0,155^{* *} \\
0,021 \\
7,381\end{array}$ & $\begin{array}{c}0,224^{* *} \\
0,022 \\
10,182\end{array}$ & $\begin{array}{c}0,284^{* *} \\
0,028 \\
10,143\end{array}$ \\
\hline Baixa superior & & - & $\begin{array}{l}0090^{* *} \\
0,021 \\
4,286\end{array}$ & $\begin{array}{l}0,159 * * \\
0023 \\
6,913\end{array}$ & $\begin{array}{l}0,219 * * \\
0,028 \\
7,821\end{array}$ \\
\hline Média inferior & & - & - & $\begin{array}{l}0,069^{* *} \\
0,022 \\
3,136\end{array}$ & $\begin{array}{l}0,129 * * \\
0,028 \\
4,607\end{array}$ \\
\hline Média superior & & 一 & - & - & $\begin{array}{l}0,060^{*} \\
0,029 \\
2,069\end{array}$ \\
\hline
\end{tabular}

* - Significante a 0,05 .

** - Significante a 0,01 .

(1) - Diferença de médlas.

(2) - Desvio-padrão de diferença.

(3) - Valor de $\mathfrak{t}$-Student. 
FERRANTE, V. L. S. B. et al. - Um modelo de análise sócio-econômica: construção e re sultados obtidos. Rev. Saúde públ., S. Paulo, 10:177-90, 1976.

Já para o índice de cárie, apesar das classes sociais diferentes terem apresentado comportamentos distintos, não se observou uma acentuada tendência à diminuição desse indice paralelamente à elevação do nível sócio-econômico (Tabela 4). Entretanto, a influência do nível sócio-econômico ainda foi significativa, com o estudo mostrando uma percentagem maior de indivíduos sem cáries para as classes superiores e também, um percentual maior da amostra com um ou mais dentes atacados pela cárie àqueles pertencentes às classes sociais inferiores (Tabela 7).

\section{CONCLUSOES}

Pelos resultados obtidos e metodologia aplicada, conclui-se que:

1) O emprego do sistema proposto para avaliação de classe social, mostrou que os escolares do $1 .^{\circ}$ grau da rede es-

\section{TABELA 7}

Percentual de individuos som indice de cárle (CPO) zero e igual ou maior que um, dentro đas várias classes sociaís

\begin{tabular}{l|l|r} 
& \multicolumn{2}{|c}{ Indice $\mathrm{CPO}$} \\
\cline { 2 - 3 } Classe social & Zero & $>1$ \\
& & \\
\hline & & 84,1 \\
Baixa inferior & $\mathbf{1 5 , 9}$ & $\mathbf{7 9 , 0}$ \\
Baixa superior & $\mathbf{2 1 , 0}$ & $\mathbf{7 4 , 5}$ \\
Média inferior & $\mathbf{2 5 , 5}$ & $\mathbf{7 8 , 8}$ \\
Média superior & $\mathbf{2 1 , 2}$ & $\mathbf{7 1 , 4}$ \\
Alta & $\mathbf{3 8 , 0}$ & \\
\hline
\end{tabular}

tadual de ensino de Araraquara pertencem, na sua maioria, às classes sociais inferiores.

2) Pode ser aceita a hierarquização da população em seis estratos sociais, a partir do conjunto de indicadores aplicados.

RSPU-B/311

Ferrante, V. L. S. B. et a1. - [A model of socio-economic analysiss its construction and obtained results]. Rev. Saúde públ., S. Paulo, 10:177-90, 1976.

SUMMary: A model of socio-economic analysis is here presented with the purpose of constructing a possible scale of society's structure and determinating the position of a certain population in it. The model was constructed from a group of indicators, previously selected as being the most significative for further evaluation of the socio-economic level of the sample. The objective of the construction of this particular model is to demonstrate the interference of socio-economic variables in the occurrence of certain oral problems. The investigation showed the following composition for the studied population: inferior low, 21.8\%; superior low, 39.9\%; inferior middle, 26.6\%; superior middle, 9.1\%; inferior high, 1.7\%; superior high, $0.5 \%$. model.

UNITERMS: Socio-economic analysis. Socio-economic level. Socio-economic 
FERrante, V. L. S. B. et al. - Um modelo de análise sócio-econômica: construção e resultados obtidos. Rev. Saúde públ., S. Paulo, 10:177-90, 1976.

\section{REFERENCIAS BIBLIOGRAFICAS}

1. CASTRO, C. L. M. - Caracterização sócio-econômica do estudante universitário: dados gerais. Rev. bras. Est. pedag., Rio de Janeiro, 46(104): 382-400, 1966.

2. COSTA PINTO, L. A. - Estructura de clases y campio social. 2.a ed. Buenos Aires, Paidos, 1971, p. 40.

3. DIAS, J. A. - Ensino médio e estrutura sócio-econômica. (Estado de São Paulo). Rio de Janeiro, Instituto $\mathrm{Na}$ cional de Estudos de Pedagogia, 1967. p. 43-4.

4. GLASS, D. V. - Social mobility in Britain. London, Routledge \& Kegan Paul, 1954. p. 29-50.

5. GUIDI, M. L. M. \& DUARTE, S. G. Um esquema de caracterização sócio-econômica. Rev. bras. Est. pedag., Rio de Janetro, $52(115): 65-82,1969$.

6. HALL, J. R. \& JONES, D. C. - The social grading occupations. $B r . J$. Sociol., London, 1:31-55, 1950.

7. HAVIGHURST, R. J. - Educação, mobilidade social e mudança social em quatro sociedades: estudo comparativo. Educ. e Cienc. Soc., $2: 118,1957$.
8. HUTCHINSON, B. - Mobilidade e trabalho: um estudo na cidade de são Paulo. Rio de Janeiro, Instituto Nacional de Estudos Pedagógicos, 1960.

9. KOENIG, S. - Elementos de sociologia. Rio de Janeiro, Zahar Edit., 1967.

10. OsSowsKI, S. - Estrutura de classes na consciência social. Rlo de Janeiro, Zahar Edit., 1964.

11. STAVENHAGEN, R. - Estratificação social e estrutura de classes. In: LUKACS, G, et al. - Estrutura de classes e estratificação social. Rio de Janeiro, Zahar Edit,, 1966. p. 120.

12. VERTUAN, V. - Contribuicão ao estudo da prevalencia da cárie dental, doença periodontal e higiene oral em escolares de diferentes classes socials. Relaçöes com a raça, sexo e idade. Araraquara, 1973. Tese - Faculdade de Farmácia e Odontologia de Araraquara.

13. WARNER, W. L. \& LUNT, P. S. - Social life of a modern community. New Haven, 1941 apud KOENIG, S. - Elementos de sociologia. Rio de Janeiro, Zahar Edit., 1967. p. 263-5.

Recebido para publicacão em 01/12/1975 Aprovado para publicacão em 05/01/1976 
FERRANTE, V. L. S. B. et al. - Um modelo de análise sócio-econômica: construção e resultados obtidos. Rev. Saúde públ., S. Paulo, 10:177-90, 1976.

\section{QUESTIONARIO UTILIZADO NESTA \\ PESQUISA}

Nome do entrevistado:

Endereço:

$$
\text { ( ) centro ( ) bairro }
$$

Relig ão:

$$
\begin{aligned}
& \text { 1- Data de nascimento: } \\
& 2 \text { - Sexo: ( )masculino ( ) feminino } \\
& 3 \text { - Estado civil: } \\
& \text { ( ) solteiro } \\
& \text { ( ) casado } \\
& \text { ( ) viúvo } \\
& \text { ( ) desquitado } \\
& \text { ( ) outro. Qual? } \\
& 4 \text { - Cor: } \\
& \text { () branca } \\
& \text { ( ) preta } \\
& \text { ( ) amarela } \\
& \text { ( ) mulata } \\
& \text { ( ) outra } \\
& 5 \text { - Nacionalidade: } \\
& \text { () português } \\
& \text { ( ) italiano } \\
& \text { ( ) japonês } \\
& \text { ( ) espanhol } \\
& \text { ( ) brasileiro } \\
& \text { ( ) outra }
\end{aligned}
$$

6 - Profissão:

( ) operário. Função:

( ) funcionário público. Função:

( ) bancário. Função:

( ) profissional livre. Função:

( ) industrial. Função:

( ) comerciante. Função:

( ) comerciário. Função:

( ) trabalho por conta própria. Ramo:

Número de empregados:

( ) outra. Qual?

7 - Posição que ocupa na familia em relação a seu chefe:

( ) o próprio chefe

( ) filho(a)

( ) sobrinho

( ) genro

( ) primo

( ) cunhado

( ) outros

8-Qual a profissão do chefe da família:

( ) operário. Função:

( ) funcionário público. Função:

( ) bancário. Função:
( ) profissional livre. Função:

( ) industrial. Função:

( ) industriário. Função:

( ) comerciante. Função:

( ) comerciário. Função:

( ) trabalha por conta própria. Ramo:

Número de empregados:

( ) outra. Qual?

9 - Qual o rendimento mensal da família:

( ) menos de 1 salário mínimo

( ) 1 salário mínimo

( ) 1 - 2 salários mínimos

( ) $2-3$ salários mínimos

( ) 3 - 4 salários mínimos

( ) $4-6$ salários mínimos

( ) $6-8$ salários mínimos

( ) 8 - 10 salários mínimos

( ) 10 - 15 salários mínimos

( ) $15-20$ salários minimos

( ) mais de 20 salários mínimos

10 - Quantos filhos o senhor(a) tem?

( ) $1-3$ filhos

( ) $3-5$ filhos

( ) $5-7$ filhos

( ) $7-10$ filhos

( ) mais de 10 filhos

11 - A renda da família provém:

( ) de renda (salário, aposentadoria) do chefe da familia Quanto?

( ) de renda (salário, aposentadoria) da esposa

( ) de renda (salário, aposentadoria) dos filhos Quantos trabalham?

( ) de renda (salário, aposentadoria) do irmão(ã)

( ) de renda que o senhor recebe Quanto?

( ) de outra fonte Qual?

12 - Grau de escolarização:

( ) analfabeto

( ) sabe ler e escrever

( ) primário completo

( ) primário incompleto

( ) I secundário completo

( ) I secundário incompleto

( ) II secundário completo

( ) II secundário incompleto

( ) superior completo

( ) superior incompleto 
FERRANTE, V. L. S. B. et al. - Um modelo de análise sócio-econômica: construção e resultados obtidos. Rev. Saúde públ., S. Paulo, 10:177-90, 1976.

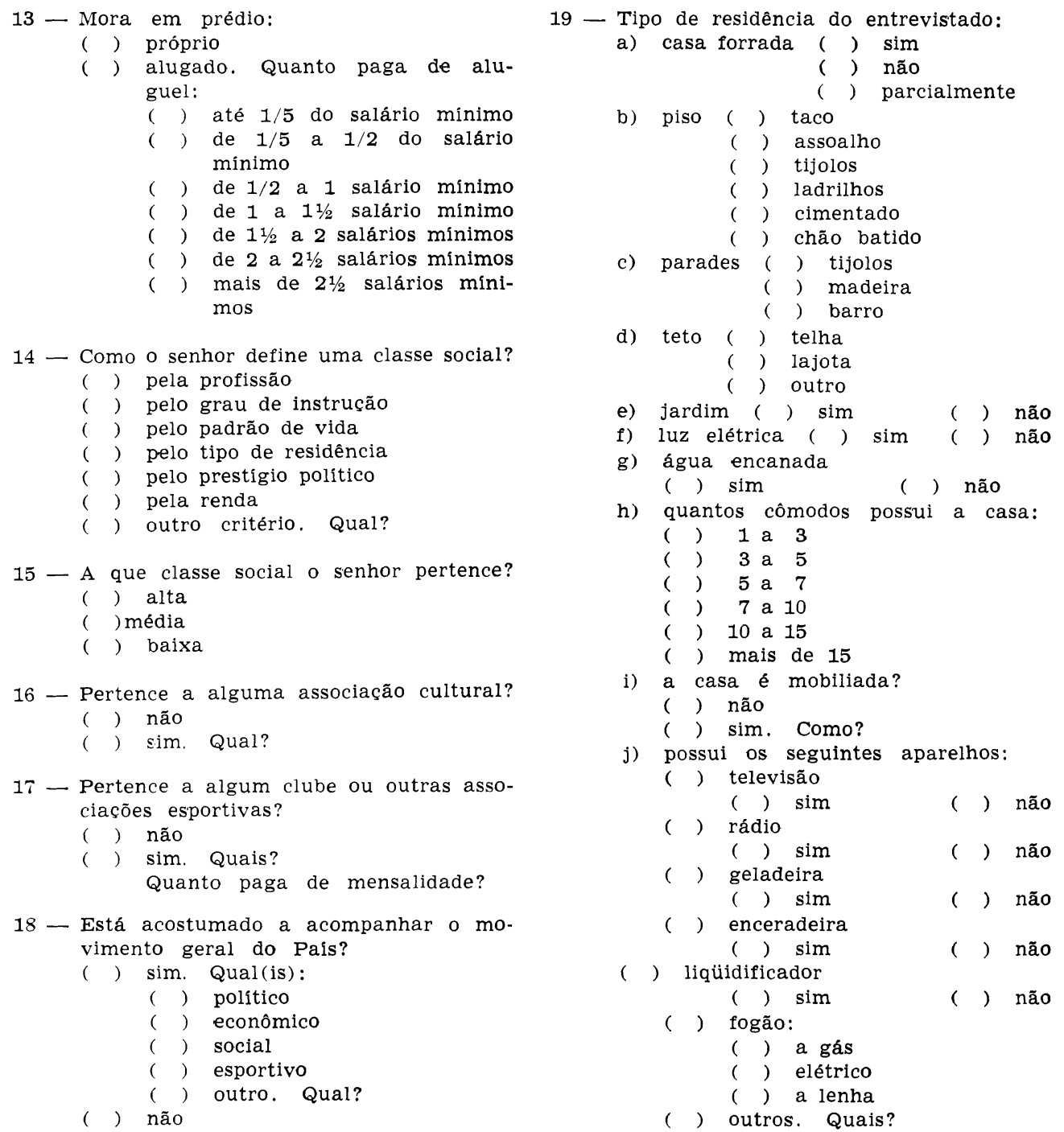

